\title{
Effects of propofol on intraoperative parathyroid hormone monitoring in patients with primary hyperparathyroidism undergoing parathyroidectomy: a randomized control trial Les effets du propofol sur le monitorage peropératoire de l'hormone parathyroïdienne chez les patients souffrant d'hyperparathyroïdisme primaire subissant une parathyroïdectomie: une étude randomisée contrôlée
}

\author{
Jonathon E. Kivela, MD · Juraj Sprung, MD, PhD • Melanie L. Richards, MD • \\ Brad S. Karon, MD, PhD $\cdot$ Roger E. Hofer, MD $\cdot$ Liedl M. LiedI, RST • \\ Darrell R. Schroeder, MS • Toby N. Weingarten, MD
}

Received: 24 January 2011/Accepted: 17 March 2011/Published online: 1 April 2011

(c) Canadian Anesthesiologists' Society 2011

\begin{abstract}
Purpose Serial measurements of parathyroid hormone (PTH) serum concentrations aid parathyroidectomy surgery. There are concerns that propofol may increase PTH concentrations and/or interfere with PTH assays. The primary purpose of this study is to determine the effects of propofol on PTH concentrations in patients with primary hyperparathyroidism and to determine its effect on PTH assays.

Methods Thirty patients with primary hyperparathyroidism were assigned randomly to induction and maintenance with either propofol or sevoflurane. Blood samples for PTH assays were obtained pre-induction, immediately after induction, ten minutes after induction,
\end{abstract}

J. E. Kivela, MD · J. Sprung, MD, PhD

R. E. Hofer, MD · L. M. Liedl, RST .

T. N. Weingarten, MD $(\bowtie)$

Department of Anesthesiology, College of Medicine, Mayo

Clinic, 200 First Street, SW, Rochester, MN 55901, USA

e-mail: weingarten.toby@mayo.edu

M. L. Richards, MD

Gastroenterologic and General Surgery, Department of Surgery,

College of Medicine, Mayo Clinic, Rochester, MN, USA

B. S. Karon, MD, PhD

Department of Laboratory Medicine and Pathology, College of Medicine, Mayo Clinic, Rochester, MN, USA

D. R. Schroeder, MS

Department of Health Sciences Research, College of Medicine, Mayo Clinic, Rochester, MN, USA and after excision of parathyroid adenoma. The primary endpoint was the PTH concentration at ten minutes after induction. This endpoint was compared between groups using analysis of covariance adjusting for pre-induction PTH. An in vitro study was performed with four different pools of PTH concentrations that were spiked with increasing concentrations of propofol. Serum PTH was measured in duplicate in each sample and analyzed using repeated measures analysis of variance.

Results At ten minutes after induction, PTH concentrations did not differ significantly between groups (least square mean difference $-7.0 \mathrm{pg} \cdot \mathrm{mL}^{-1} ; 95 \%$ confidence interval, -34.2 to +20.2$)$. The PTH level in vitro did not change significantly with increasing propofol concentrations.

Discussion Parathyroid hormone concentrations in patients with primary hyperparathyroidism were not affected by the type of anesthesia (propofol vs sevoflurane). Furthermore, propofol was found not to interfere with PTH assays at clinically relevant concentrations. There is no evidence to support the avoidance of a propofol anesthetic for parathyroid surgery.

\section{Résumé}

Objectif Les mesures en série des concentrations sériques de l'hormone parathyroïlienne (PTH) sont utiles pendant une chirurgie de parathyroïlectomie. Certaines inquiétudes ont été émises quant à la propension $d u$ propofol à augmenter les concentrations de PTH et/ou à fausser les analyses de PTH. L'objectif principal de cette étude était d'identifier les effets du propofol sur les 
concentrations de PTH chez les patients atteints d'hyperparathyroïdisme primaire et de déterminer son effet sur les analyses de PTH.

Méthode Trente patients atteints d'hyperparathyroidisme primaire ont été randomisés à recevoir soit du propofol soit du sévoflurane pour l'induction et le maintien de l'anesthésie. Des échantillons de sang pour des analyses de PTH ont été obtenus avant l'induction, immédiatement après l'induction, dix minutes après l'induction et après l'excision de l'adénome parathyroïlien. Le critère d'évaluation principal était la concentration de PTH dix minutes après l'induction. Ce résultat a été comparé entre les groupes à l'aide d'une analyse de covariance tenant compte de la PTH avant induction. Une étude in vitro a été réalisée avec quatre différents échantillons regroupés de différentes concentrations de PTH auxquels on a ajouté des concentrations croissantes de propofol. La PTH sérique a été mesurée en double dans chaque échantillon et analysée à l'aide d'analyse répétée des mesures de variance.

Résultats Dix minutes après l'induction, les concentrations de PTH n'étaient pas significativement différentes entre les groupes (racine carrée des moindres carrés de la différence $-7,0 \mathrm{pg} \cdot \mathrm{mL}^{-1}$; intervalle de confiance $95 \%,-34,2 \grave{a}+20,2)$. Le niveau in vitro de PTH n'a pas subi de changement significatif avec des concentrations croissantes de propofol.

Discussion Les concentrations de l'hormone parathyrö̈dienne chez les patients atteints d'hyperparathyroïdisme primaire n'ont pas étéaffectées par le type d'anesthésie (propofol vs sévoflurane). En outre, il a été démontré que le propofol ne faussait pas les analyses de PTH à des concentrations pertinentes d'un point de vue clinique. Aucune donnée probante ne recommande d'éviter une anesthésie au propofol pour la chirurgie de la parathyroïde.

The surgical management of primary hyperparathyroidism (HPT) is aided by intraoperative serial measurements of circulating parathyroid hormone (PTH) to verify the removal of pathological parathyroid tissue. Precise measurement of PTH concentrations is an important step in decision-making during removal of parathyroid adenoma, and it is a key tool to determine complete resection of the hyperfunctioning parathyroid gland/s. Rapid assays of PTH approved by the Food and Drug Administration are commercially available and in widespread practice. Parathyroidectomy is a relatively minor procedure and wellsuited for an ambulatory surgical setting. The use of total intravenous anesthetic with propofol has been shown to offer advantages over inhalation anesthetics in terms of lower rates of postoperative nausea and vomiting. ${ }^{1}$ However, there are concerns that propofol interferes with intraoperative PTH measurements. ${ }^{2,3}$ Administration of propofol to healthy volunteers resulted in a dose-dependent elevation of serum PTH to the range observed in patients with primary HPT. ${ }^{2}$ However, regulation of PTH secretion is altered in primary HPT, and the effects of propofol on serum concentrations of PTH in patients with primary HPT has not been evaluated. An additional concern was raised by an in vitro study where it was found that propofol causes negative interference with PTH assay, albeit at supratherapeutic concentrations. ${ }^{3}$ This finding resulted in the recommendation that continuous infusions of propofol must be stopped five minutes prior to PTH sampling. ${ }^{3}$ However, it is unknown whether propofol in clinically relevant concentrations also affects the accuracy of PTH assays.

The primary purpose of this study was to determine whether using propofol as a primary anesthetic affects serum PTH concentrations in patients with primary HPT. A secondary aim was to examine whether clinically relevant propofol concentrations interfere with the accuracy of PTH assay in vitro.

\section{Methods}

The Mayo Clinic Institutional Review Board approved this investigation, and each subject gave written informed consent. Patients were approached by a research nurse at the time of their preoperative examination and were screened for potential inclusion in the study. Inclusion criteria included all competent patients older than $18 \mathrm{yr}$ who were scheduled to undergo an elective parathyroidectomy for primary HPT by a single surgeon (M.L.R.). We excluded patients with prior neck operations, those with secondary or tertiary HPT, or those with allergies or contraindications to any of the anesthetic agents used. A randomization schedule was generated by the Division of Biomedical Statistics and Informatics using blocks of size $n=4$ to ensure that the number of subjects assigned to each treatment group was balanced over time. Sequentially numbered sealed envelopes containing the randomized treatment assignments were prepared using this randomization schedule. The treatment assignment for a given patient was determined at the beginning of the operation by opening the next sequentially numbered envelope.

Anesthetic management

In order to prevent or minimize anesthetic induction hypotension, all patients received an intravenous infusion of $0.9 \%$ normal saline $500 \mathrm{~mL}$ prior to the start of anesthesia. During the first $30 \mathrm{~min}$ after anesthetic induction, normal saline infusions were limited to $<500 \mathrm{~mL}$. 
After application of standard American Society of Anesthesiologists monitors, patients were given light sedation (maximum midazolam $2 \mathrm{mg} i v$ and fentanyl up to $100 \mu \mathrm{g} i \mathrm{v})$ as clinically required according to the staff anesthesiologist. Next, an $18 \mathrm{G}$ intravenous catheter was inserted into the antecubital vein of the patient's arm contralateral to the arm that contained the initial peripheral intravenous line. The antecubital intravenous catheter was attached to a standard flush system used for arterial line monitoring (pressurized $[300 \mathrm{mmHg}$ ] heparinized normal saline [2 $\mathrm{U}$ heparin per $1 \mathrm{~mL}$ of normal saline] attached to a flush system with a delivery of $1 \mathrm{~mL} \cdot \mathrm{hr}^{-1}$ ). This intravenous was used to draw the blood for measurement of serum PTH concentrations and was not used for intravenous medication or for fluid administration.

\section{Propofol group}

In the propofol group, anesthesia was induced with fentanyl $2 \mu \mathrm{g} \cdot \mathrm{kg}^{-1} i v$ and propofol $2 \mathrm{mg} \cdot \mathrm{kg}^{-1} i v$ according to ideal body weight. The propofol used in this study was the commercially available formulation (Diprivan ${ }^{\circledR} 1 \%$ Injectable Emulsion, Abraxis Pharmaceutical Products, Schaumburg, IL, USA) of propofol in a liquid emulsion containing soybean oil, glycerol, egg lecithin, sodium hydroxide, and disodium edetate (EDTA) as an antimicrobial. Succinylcholine $1.5 \mathrm{mg} \cdot \mathrm{kg}^{-1} i v$ (ideal body weight) was administered to facilitate tracheal intubation. Anesthesia was maintained by a continuous infusion of propofol at $160 \mu \mathrm{g} \cdot \mathrm{kg}^{-1} \cdot \mathrm{min}^{-1}$ for the first ten minutes of the anesthetic. This continuous infusion was initiated at the same time with the induction bolus dose of propofol. Since the investigator was unaware whether propofol affects PTH concentrations, the propofol infusion was discontinued after ten minutes to remove any potential influence on clinical decision-making. This period of time was chosen so that the infusion of the study drug was completed prior to the skin incision; therefore, the operation was completed according to routine clinical practice with anesthesia maintained with inhalational agents.

\section{Inhalational group}

In the control (inhalational) group, patients received fentanyl $2 \mu \mathrm{g} \cdot \mathrm{kg}^{-1}$ followed by nitrous oxide and sevoflurane. Succinylcholine $1.5 \mathrm{mg} \cdot \mathrm{kg}^{-1}$ iv was administered to facilitate tracheal intubation (dose adjusted to ideal body weight). Anesthesia was maintained by sevoflurane in oxygen and air for the remainder of the study and surgery.

\section{Data collection}

Blood samples for serum PTH assays were collected at four points in time. The procedure for collecting the blood samples followed our standard institutional clinical guidelines. Samples were collected from the second intravenous line after first drawing and disposing of $10 \mathrm{~mL}$ of venous blood (the line volume is $3 \mathrm{~mL}$ ), and the samples were placed in a 3-mL EDTA-containing vacuum tube with a minimum volume of $1.5 \mathrm{~mL}$. The samples were centrifuged at 7,200 x $\mathrm{g}$ for two minutes and analyzed using the Roche STAT PTH reagent on a Cobas e 411 Analyzer (Roche Diagnostics, Indianapolis, IN, USA). The assay has a precision (in percent coefficient of variation) of $3 \%$ to $5 \%$ when external control materials covering the reportable range of the assay are analyzed over time. In the present study, we report values of four PTH concentrations. The baseline (Sample \#1) PTH sample was obtained prior to the induction of anesthesia and after completion of the $500 \mathrm{~mL}$ saline load, and Sample \#2 PTH level was obtained after tracheal intubation. Ten minutes after tracheal intubation, Sample \#3 PTH level was obtained, and Sample \#4 was drawn at the closure of neck incision to reconfirm the PTH decrease to $>50 \%$ from the baseline. All blood samples were separated into serum by using the standardized approach and were then refrigerated and stored under identical conditions at the Mayo Clinic Central Lab.

\section{In vitro study}

An in vitro study was also performed to determine whether propofol interferes with PTH monitoring. These experiments were performed on four pools of EDTA plasma or serum with different baseline PTH concentrations. Each pool was prepared from ten to 20 separate serums or EDTA samples as follows: 1) EDTA plasma from ten healthy volunteers was used to create a pool of plasma of normal PTH concentration (approximately $30 \mathrm{pg} \cdot \mathrm{mL}^{-1}$ ); 2) residual EDTA plasma was pooled from the highest ten baseline samples in patients with primary HPT (approx $90 \mathrm{pg} \cdot \mathrm{mL}^{-1}$ ); and finally, stored serum from the Mayo Clinical Laboratories was used to create one additional pool each of 3 ) high PTH concentration $\left(\approx 150 \mathrm{pg} \cdot \mathrm{mL}^{-1}\right)$ and 4$)$ very high $\mathrm{PTH}$ concentration $\left(\approx 450 \mathrm{pg} \cdot \mathrm{mL}^{-1}\right)$. Whole blood was centrifuged at $4,400 \times \mathrm{g}$ for two minutes to produce EDTA plasma or at $1,500 \times \mathrm{g}$ for ten minutes to produce serum. The EDTA plasma from healthy volunteers (pool 1) was collected, centrifuged, pooled, and analyzed on the same day. Serum and EDTA samples for pools 2 to 4 were frozen at $-70^{\circ} \mathrm{C}$ for up to six months until samples were pooled and analyzed.

Propofol $10 \mathrm{mg} \cdot \mathrm{mL}^{-1}$ was first diluted ten times in normal saline to create a $1 \mathrm{mg} \cdot \mathrm{mL}^{-1}$ working stock solution. Five $1,000 \mu \mathrm{L}$ aliquots were created from each plasma or serum pool described above, and 0 to $25 \mu \mathrm{L}$ of propofol stock solution were added to $1,000 \mu \mathrm{L}$ aliquots of the pools to achieve clinically relevant concentrations: $2.6 \mu \mathrm{g} \cdot \mathrm{mL}^{-1}$ (sedation dose), $5 \mu \mathrm{g} \cdot \mathrm{mL}^{-1}$ (maintenance 
dose), $10 \mu \mathrm{g} \cdot \mathrm{mL}^{-1}$ (induction dose), and $25 \mu \mathrm{g} \cdot \mathrm{mL}^{-1}$ (supratherapeutic dose). Samples were mixed on a rocker for ten minutes, and the PTH concentrations in the different sample pools at different concentrations of propofol were measured in duplicate using the Roche STAT PTH assay on the Cobas e 411. Since the maximum dilution of patient sample pools by propofol solution was only $2.5 \%(25 \mu \mathrm{L}$ into 1,000), there was no correction of PTH results for dilution effects of the propofol.

\section{Statistical analyses}

Data were summarized using mean and standard deviation or median and interquartile range for continuous variables and frequency percentages for categorical variables. All analyses were performed using $\mathrm{SAS}{ }^{\circledR}$ version 9.2 (SAS Institute Inc, Cary, NC, USA). The PTH concentrations immediately after induction and at ten minutes after induction were compared between groups using analysis of covariance with baseline values included as the covariate. For these analyses, distribution assumptions were assessed by visual inspection of residual plots. Results are summarized by presenting the least square mean difference between groups (propofol minus sevoflurane) adjusting for baseline, corresponding $95 \%$ confidence interval, and $P$ value. Although both of these time points were of interest, the comparison between groups at ten minutes after induction was chosen a priori as the primary comparison. In vitro PTH measurements were analyzed using a mixed linear model (PROC MIXED) to assess whether PTH concentrations changed with increasing concentrations of propofol. For this analysis, log (PTH) was the dependent variable, propofol concentration was the independent variable, and serum pool was a repeated factor with a lag-1 autoregressive structure used to model the correlation of measurements within serum pools. All reported $P$ values are two-sided.

A sample size of $n=15$ per group was chosen for this study after weighing statistical considerations along with time and resource constraints inherent in studying this unique patient population. This sample size is similar to that used in a previous study comparing PTH concentrations in patients with secondary hyperparathyroidism (renal failure) receiving propofol $v s$ midazolam. ${ }^{4}$

\section{Results}

The study was conducted from March 15, 2010 to August 10, 2010. Forty patients with primary HPT were screened for this study. Two patients were excluded because of selfreported egg allergy, and eight patients declined to participate in this study. The remaining 30 patients with primary HPT undergoing parathyroidectomy were enrolled and randomized to receive either propofol $(n=15)$ or sevoflurane/nitrous oxide anesthetic $(n=15)$. Demographic and clinical characteristics were similar between the two groups (Table 1). The majority of patients in both groups were female, 13 in the propofol group and 14 in the inhalational group. Most patients were American Society of Anesthesiologists' physical status II (13 in the propofol group and 11 in the inhalational group). In Fig. 1, PTH concentrations are shown at baseline, immediately after induction, ten minutes after induction, and after resection of adenoma. Patients who received propofol were observed to have a higher mean baseline PTH concentration (Table 2). From analysis of covariance adjusting for baseline, PTH concentrations immediately and ten minutes post tracheal intubation were similar between groups (Table 2). After resection of the parathyroid adenoma(s), serum PTH concentrations declined $>50 \%$ in all patients, thus clinically confirming successful removal of parathyroid adenoma (Fig. 1).

\section{In vitro experiment}

Parathyroid hormone samples for the in vitro experiments assessing for interference with clinically relevant propofol concentrations were analyzed in duplicate (to minimize effects of random variation in PTH measurement) on four pools of EDTA plasma or serum with different baseline PTH concentrations. Specifically, the PTH concentrations were as follows: $28.7 \mathrm{pg} \cdot \mathrm{mL}^{-1}$ in pooled plasma from healthy individuals (volunteers), $92.7 \mathrm{pg} \cdot \mathrm{mL}^{-1}$ in pools from our patient population, and $154.6 \mathrm{pg} \cdot \mathrm{mL}^{-1}$ and $459.3 \mathrm{pg} \cdot \mathrm{mL}^{-1}$ in pools with high and very high PTH

Table 1 Demographic and clinical characteristics of study subjects

\begin{tabular}{lcc}
\hline & $\begin{array}{l}\text { Propofol } \\
n=15\end{array}$ & $\begin{array}{l}\text { Volatile } \\
n=15\end{array}$ \\
\hline Age, yr mean (SD) & $60(11)$ & $63(11)$ \\
Female, $n(\%)$ & $13(86.7)$ & $14(93.3)$ \\
BMI, kg.m ${ }^{-2}$ mean (SD) & $31.3(5.9)$ & $30.8(7.2)$ \\
ASA physical status, $n(\%)$ & & \\
II & $13(86.7)$ & $11(73.3)$ \\
III & $2(13.3)$ & $4(26.7)$ \\
Beta blockers, $n(\%)$ & $4(26.7)$ & $5(33.3)$ \\
Ca channel blockers, $n(\%)$ & $2(13.3)$ & $2(13.3)$ \\
Adenoma resected, $n(\%)$ & & $13(86.7)$ \\
One & $14(93.3)$ & $2(13.3)$ \\
Two & $1(6.7)$ & PTH \\
\hline
\end{tabular}

$\mathrm{SD}=$ standard deviation; $\mathrm{BMI}=$ body mass index $; \quad \mathrm{PTH}=$ parathyroid hormone level; ASA $=$ American Society of Anesthesiologists 


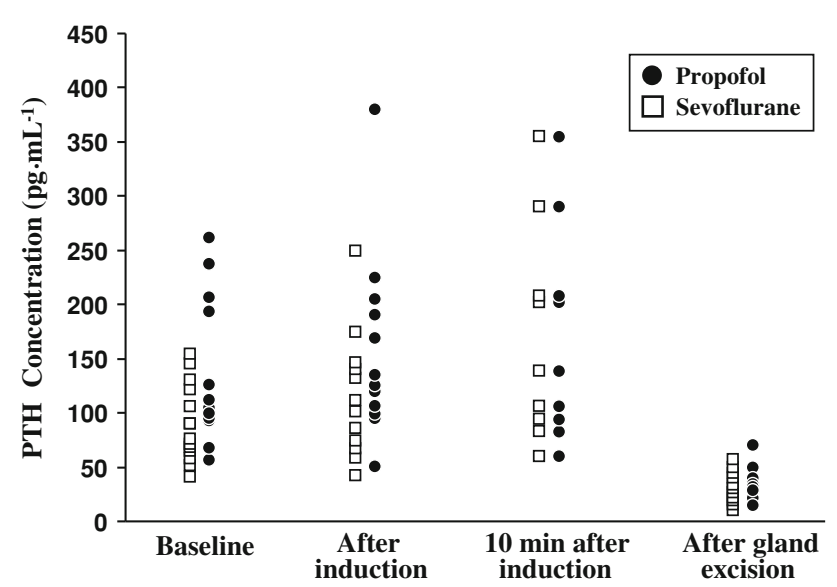

Fig. 1 Patient parathyroid concentrations are presented according to treatment group: at baseline, immediately after induction, ten minutes after induction, and after resection of adenoma

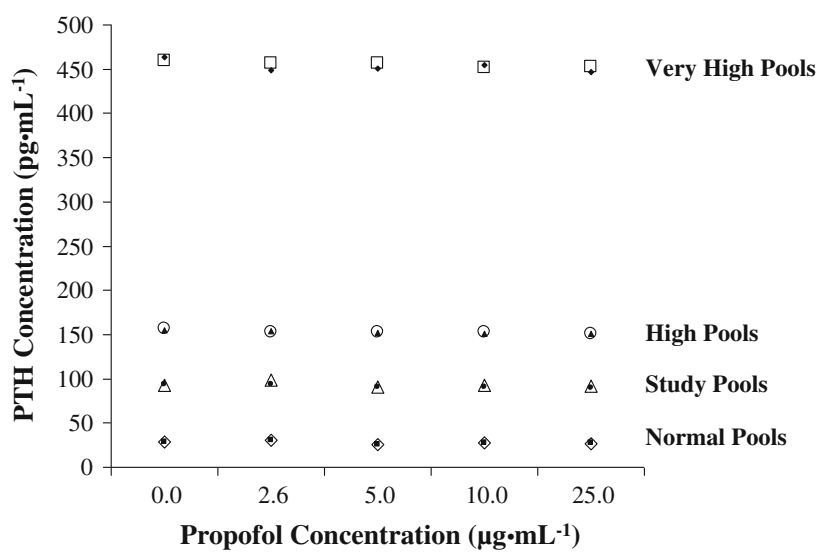

Fig. 2 In vitro assays of parathyroid hormone concentrations measured in duplicate from four serum pools before and after adding propofol at four different concentrations (see "Methods")

Table 2 Serum parathyroid hormone concentrations and between group differences

\begin{tabular}{|c|c|c|c|c|c|}
\hline \multirow[t]{2}{*}{ Timing of PTH sample } & \multirow{2}{*}{$\begin{array}{l}\text { Propofol serum PTH }\left(\mathrm{pg} \cdot \mathrm{mL}^{-1}\right) \\
n=15\end{array}$} & \multirow{2}{*}{$\begin{array}{l}\text { Sevoflurane serum PTH }\left(\mathrm{pg} \cdot \mathrm{mL}^{-1}\right) \\
n=15\end{array}$} & \multicolumn{3}{|c|}{ Mean difference adjusted for baseline* } \\
\hline & & & Estimate & $(95 \% \mathrm{CI})$ & $P$ value \\
\hline \multicolumn{6}{|c|}{ Baseline (before anesthesia) } \\
\hline Mean (SD) & $132.3(63.0)$ & $96.3(38.2)$ & - & - & - \\
\hline Median (IQR) & $104(97,196)$ & $93(60,129)$ & & & \\
\hline \multicolumn{6}{|l|}{ Anesthesia induction } \\
\hline Mean (SD) & $151.2(79.3)$ & $111.1(53.7)$ & +0.7 & $(-27.5$ to +28.9$)$ & 0.961 \\
\hline Median (IQR) & $123(101,193)$ & $92(72,142)$ & & & \\
\hline \multicolumn{6}{|c|}{ Ten minutes after induction } \\
\hline Mean (SD) & $143.8(85.6)$ & $111.1(54.4)$ & -7.0 & $(-34.2$ to +20.2$)$ & 0.619 \\
\hline Median (IQR) & $104(89,204)$ & $102(73,126)$ & & & \\
\hline
\end{tabular}

Study Group data are mean \pm standard deviation $(\mathrm{SD})$ and median (interquartile range $[\mathrm{IQR}])$; *Data at each post baseline time period were analyzed using analysis of covariance with baseline values included as the covariate. Results are summarized by presenting the least square mean difference between groups (propofol minus sevoflurane), corresponding 95\% confidence interval (CI), and $P$ value

PTH $=$ parathyroid hormone level

concentrations, respectively (see "Methods"). Duplicate measurements were within the precision limits of the assay, i.e., $3 \%-5 \%$ (Fig. 2). There was no meaningful change in the PTH concentrations with increasing propofol concentrations. Decreases in PTH concentration between the baseline and the highest concentration of propofol tested were $2 \%-3 \%$ in pools containing PTH concentrations of $92.7 \mathrm{pg} \cdot \mathrm{mL}^{-1}, 154.6 \mathrm{pg} \cdot \mathrm{mL}^{-1}$, and $459.3 \mathrm{pg} \cdot \mathrm{mL}^{-1}$, consistent with the effect of a $2.5 \%$ sample dilution by the added propofol. The normal $\left(28.7 \mathrm{pg} \cdot \mathrm{mL}^{-1}\right)$ pool demonstrated a $5.7 \%$ decrease between baseline and the highest $\left(25 \mu \mathrm{g} \cdot \mathrm{mL}^{-1}\right.$ ) propofol samples, but this was still close to the limits of precision of the assay $(3 \%-5 \%)$. Thus, we could demonstrate no substantial analytical interference by propofol at physiologic concentrations (Fig. 2).

\section{Discussion}

Our main finding is that the PTH concentrations in patients with primary HPT were not affected by the type of anesthesia (propofol vs sevoflurane). At ten minutes post induction, the mean difference between groups (propofol minus sevoflurane) was $-7.0 \mathrm{pg} \cdot \mathrm{mL}^{-1}$ (95\% confidence interval, -34.2 to +20.2 ). A difference in PTH of this size is not of sufficient magnitude to interfere with clinical decision-making regarding successful removal of hyperactive adenoma in patients with primary hyperparathyroidism. Furthermore, at clinically relevant concentrations, propofol did not interfere with our PTH assay. These results suggest that there is no need to avoid propofol during parathyroid surgery as previously suggested. ${ }^{3}$ 
Whether propofol affects parathyroid serum concentrations or not is presently controversial. ${ }^{2,4-6}$ In healthy volunteers sedated with propofol serum, PTH increased in a dosedependent fashion while serum calcium concentrations remained unchanged. $^{2}$ At propofol infusion of $200 \mu \mathrm{g} \cdot \mathrm{kg}^{-1} \cdot \mathrm{min}^{-1}$, serum PTH concentrations increased $40 \%$ from baseline to values that could be encountered in patients with primary HPT. ${ }^{2}$ However, similar results were not obtained in other reports. In two studies of critically ill patients undergoing mechanical ventilation, a decline in serum PTH was observed over a span of several days of propofol sedation. ${ }^{5,6}$ In contrast, propofol sedation did not affect serum PTH in patients with secondary HPT. ${ }^{4}$ Wahr et al. ${ }^{7}$ postulated that the found increase in serum PTH in patients undergoing cardiac surgery and anesthesia with propofol was in response to either hypocalcemia or catecholamine release.

Serum PTH concentrations are known to increase in healthy subjects after administration of epinephrine. ${ }^{8}$ Mean PTH concentrations in our patients increased in response to anesthetic induction (Table 2). The catecholamine surge that occurs in response to tracheal intubation ${ }^{9,10}$ has been shown to stimulate the PTH secretion. ${ }^{11}$ Mahajna et al. ${ }^{11}$ reported a large increase in serum PTH in patients with normal parathyroid function; however, only female patients with primary HPT experienced a modest albeit statistically significant increase in serum PTH, while this increase was not significant in patients with secondary HPT. This suggests that the rise in serum PTH induced by catecholamines in patients with primary or secondary HPT may be blunted. Indeed, even though human adenomatous parathyroid tissue responded to $\beta$-adrenergic stimulation, it has been shown that $38 \%$ of adenomatous parathyroid tissue did not respond. $^{12}$ In normal individuals, control of the PTH secretion is mediated by a direct interaction between extracellular calcium and the $\mathrm{G}$ protein-coupled calciumsensing receptors ( $\mathrm{CaRs}$ ) located on the parathyroid cell surface. ${ }^{13}$ In patients with primary HPT, the number of CaRs is reduced on the surface of affected parathyroid gland cells, ${ }^{14}$ but the function of an individual $\mathrm{CaR}$ is unchanged. This results in the PTH-Ca ${ }^{2+}$ set point being shifted to the right and the abnormal parathyroid tissue subsequently hypertrophying and creating an adenoma in order to adjust to this new set point. ${ }^{14}$ Therefore, in discussing changes in PTH concentrations during anesthesia (stress), it is important to know whether the patient has normal PTH function.

Sokoll et $\mathrm{al}^{3}{ }^{3}$ suggested that propofol interferes negatively with some PTH measurement assays, although they did not investigate the PTH method used in our study. They observed interference at propofol concentrations 50 times greater than the observed serum level in patients following an anesthetic induction dose of propofol ${ }^{15}$ and 20-fold higher than the highest concentration tested in our in vitro experiments. Sokoll et al. ${ }^{3}$ tested $0.1 \%$ to $40 \%$ undiluted propofol $10 \mathrm{mg} \cdot \mathrm{mL}^{-1}$ in patient specimens, and they found a negative interference when patient samples contained supraphysiologic propofol concentrations. Interestingly, Zaloga et $\mathrm{al}^{2}$ postulated that the increase in PTH in response to propofol administration could be due to a positive interference by propofol with the PTH assay, an effect that is opposite from the negative interference reported by Sokoll et al. ${ }^{3}$ The authors speculated that this positive interference was a function of its high lipid content; however, this hypothesis is unlikely as hyperlipidemia in patients administered total parenteral nutrition does not alter measurements of PTH. ${ }^{3}$ Our results indicate that propofol concentrations typically encountered in patients undergoing total intravenous anesthesia should not interfere with serum PTH measurements. In our view, our in vitro results negate concerns of interference of PTH assays when propofol is in clinical use, and there is a limited basis on which to follow previous recommendations to discontinue propofol five to ten minutes before the PTH measurements.

This study has several limitations. We were unable to separate the potential effect of endotracheal intubation on PTH concentrations from the potential effect of specific anesthetics used. Despite this constraint, our observations are clinically relevant as endotracheal intubation is inseparable from the use of induction drugs. Another limitation is the predominantly female study cohort. Mahajna et al. noted previously that only female subjects with primary HPT experienced increases in serum PTH concentrations with endotracheal intubation. ${ }^{11}$ The possibility exists that there may be substantial differences between sexes in PTH responses to stress. Finally, we assessed the potential for in vitro interference by propofol using only one of several available rapid PTH assays.

In conclusion, serum PTH concentrations in patients with primary HPT were not affected by the type of anesthesia (propofol vs sevoflurane) and at clinically relevant serum concentrations, indicating that propofol does not interfere with our PTH assay. Therefore, propofol can be used as a primary anesthetic during parathyroidectomy for primary HPT.

Financial support This publication was made possible by the Mayo Clinic Center for Translational Science Activities (CTSA) through grant number UL1 RR024150 from the National Center for Research Resources (NCRR), a component of the National Institutes of Health (NIH), and the Mayo Clinic Hospital Clinical Laboratory.

Conflicts of interest None declared.

\section{References}

1. Sonner JM, Hynson JM, Clark O, Katz JA. Nausea and vomiting following thyroid and parathyroid surgery. J Clin Anesth 1997; 9: 398-402. 
2. Zaloga GP, Youngs E, Teres D. Propofol-containing sedatives increase levels of parathyroid hormone. Intensive Care Med 2000; 26(Suppl 4): S405-12.

3. Sokoll LJ, Drew H, Udelsman R. Intraoperative parathyroid hormone analysis: a study of 200 consecutive cases. Clin Chem 2000; 46: 1662-8.

4. Sippel RS, Becker YT, Odorico JS, Springman SR, Chen H. Does propofol anesthesia affect intraoperative parathyroid hormone levels? A randomized, prospective trial. Surgery 2004; 136: 1138-42.

5. Barr J, Zaloga GP, Haupt MT, et al. Cation metabolism during propofol sedation with and without EDTA in patients with impaired renal function. Intensive Care Med 2000; 26(Suppl 4): S433-42.

6. Herr DL, Kelly K, Hall JB, et al. Safety and efficacy of propofol with EDTA when used for sedation of surgical intensive care unit patients. Intensive Care Med 2000; 26(Suppl 4): S452-62.

7. Wahr J, Vender J, Gilbert HC, Spiess B, Horrow JC, Maddi R. Effect of propofol with and without EDTA on haemodynamics and calcium and magnesium homeostasis during and after cardiac surgery. Intensive Care Med 2000; 26(Suppl 4): S443-51.

8. Ljunhgall S, Akerstrom G, Benson L, Hetta J, Rudberg C, Wide L. Effects of epinephrine and norepinephrine on serum parathyroid hormone and calcium in normal subjects. Exp Clin Endocrinol 1984; 84: 313-8.
9. Derbyshire DR, Chmielewski A, Fell D, Vater M, Achola K, Smith $G$. Plasma catecholamine responses to tracheal intubation. Br J Anaesth 1983; 55: 855-60.

10. Pernerstorfer T, Krafft P, Fitzgerald RD, et al. Stress response to tracheal intubation: direct laryngoscopy compared with blind oral intubation. Anaesthesia 1995; 50: 17-22.

11. Mahajna A, Barak M, Mekel M, Ish-Shalom S, Krausz MM. Parathyroid hormone response to tracheal intubation in hyperparathyroid patients and normal subjects. Endocr J 2005; 52: 715-9.

12. Kane-Johnson N, Strasik L, Orwoll ES. Dissociation of secretory responses to low-calcium and beta-adrenergic stimulation in primary hyperparathyroidism. Metabolism 1987; 36: 580-4.

13. Brown EM, Gamba G, Riccardi D, et al. Cloning and characterization of an extracellular $\mathrm{Ca}(2+)$-sensing receptor from bovine parathyroid. Nature 1993; 366: 575-80.

14. Cetani F, Picone A, Cerrai P, et al. Parathyroid expression of calcium-sensing receptor protein and in vivo parathyroid hormone$\mathrm{Ca}(2+)$ set-point in patients with primary hyperparathyroidism. J Clin Endocrinol Metab 2000; 85: 4789-94.

15. Schuttler J, Stoeckel H, Schwilden H. Pharmacokinetic and pharmacodynamic modelling of propofol ('Diprivan') in volunteers and surgical patients. Postgrad Med J 1985; 61(Suppl 3): 53-4. 